\title{
Identification of Streptococcus suis Meningitis by Direct Triplex Real-Time PCR, Burkina Faso
}

\author{
Mahamoudou Ouattara, Mamadou Tamboura, Dinanibe Kambire, Mahamoudou Sanou, \\ Kalifa Ouattara, Malika Congo, Adama Kaboré, Soufiane Sanou, Elie Kabré, Sable Sharpley, \\ Theresa Tran, Stephanie Schwartz, Soumeya Ouangraoua, Abdoul-salam Ouedraogo, \\ Lassana Sangaré, Rasmata Ouedraogo-Traore, Cynthia G. Whitney, Bernard Beall
}

Meningitis confirmation in Burkina Faso uses PCR for detecting Streptococcus pneumoniae, Neisseria meningitidis, or Hemophilus influenzae. We identified 38 cases of meningitis among 590 that were PCR-positive for 3 nonpneumococcal streptococcal pathogens, including 21 cases of Streptococcus suis. Among the country's 13 regions, 10 had S. suis-positive cases.

Streptococcus suis is a commensal organism of the $S$ upper respiratory tract of pigs that can occasionally cause severe invasive infections in these animals $(1,2)$. The bacterium also can infect humans who have close contact with pigs or pork products, leading to serious diseases such as meningitis, endocarditis, and sepsis (3). S. suis can survive in dust, manure, and pig carcasses for days or even weeks under optimal conditions; therefore, the working environments in slaughterhouses and farms can be a source of human infection $(3,4)$. Meningitis is the most common clinical manifestation of $S$. suis infection in humans and has an estimated case-fatality rate of $3 \%(2)$. Whereas this zoonotic pathogen is among the leading causes of adult meningitis in some countries of Southeast Asia (5), its incidence in Africa is largely unknown. We report 21 retrospectively confirmed cases of $S$. suis meningitis in Burkina Faso.

Author affiliations: Centers for Disease Control and Prevention, Atlanta, Georgia, USA (M. Ouattara, S. Sharpley, T. Tran,

S. Schwartz, C.G. Whitney, B. Beall); Centre Hospitalier Universitaire Pédiatrique Charles de Gaulle, Ouagadougou, Burkina Faso (M. Tamboura, D. Kambire, M. Sanou,

R. Ouedraogo-Traore); Centre Hospitalier Universitaire Yalgado Ouédraogo, Ouagadougou (K. Ouattara, M. Congo, L. Sangaré); Centre Hospitalier Universitaire Sanon-Sourô, Bobo-Dioulasso,

Burkina Faso (A. Kaboré, S. Sanou, A-s, Ouedraogo);

Centre-Muraz, Bobo-Dioulasso (E. Kabré, S. Ouangraoua)

DOI: https://doi.org/10.3201/eid2609.200203

\section{The Study}

Burkina Faso conducts nationwide case-based surveillance for bacterial meningitis. Cerebrospinal fluid (CSF) samples collected from patients with suspected meningitis are sent to 1 of 5 national laboratories for confirmation by culture and real-time PCR testing (6). Because of multiple challenges encountered by the laboratories in isolating bacteria from CSF, the confirmation of meningitis cases relies heavily on molecular detection (6). The real-time PCR assay currently used at the national laboratories only detects Streptococcus pneumoniae, Neisseria meningitidis, and Haemophilus influenzae. Between 2015 and 2018, the national laboratories tested 7,174 CSF samples from patients with suspected meningitis nationwide. Of these, 4,930 $(68.7 \%)$ were PCR-negative for S. pneumoniae, N. meningitidis, and $H$. influenzae. To further investigate suspected meningitis cases that were PCR-negative after testing for the 3 pathogens, a subset of specimens was selected for additional screening based on leukocytes counts $\geq 50$ cells $/ \mathrm{mm}^{3}$. In total, 912 PCR-negative specimens were available for the study; among these, 590 fit the selection criteria. The specimens were retested by using a triplex direct real-time PCR that was designed for the simultaneous detection of Streptococcus agalactiae (group B Streptococcus [GBS]), S. pyogenes (group A Streptococcus [GAS]), and S. suis. The nucleotide sequences and final concentrations of the primers and probes used in this assay (Table 1) were identical to those used in singleplex real-time PCR methods (7-10), with the exception that FAM was replaced by HEX as the reporter dye for $c f b$-specific probes for the GBS target and by Cy5 as the reporter dye for spyspecific probes for the GAS target. Each reaction was prepared in a final volume of $25 \mu \mathrm{L}$, including $1 \mu \mathrm{L}$ of each primer and probe, $2 \mu \mathrm{L}$ of CSF as DNA template, $12.5 \mu \mathrm{L}$ of PerfeCta MultiPlex qPCR ToughMix mastermix (QuantaBio, https://www.quantabio.com), 
Table 1. Sequences and concentrations of primers and probes used to detect Streptococcus suis, S. agalactiae, and S. pyogenes, Burkina Faso*

\begin{tabular}{|c|c|c|c|c|}
\hline $\begin{array}{l}\text { Target } \\
\text { gene }\end{array}$ & Forward primer, $5^{\prime} \rightarrow 3^{\prime}$ & Reverse primer, $5^{\prime} \rightarrow 3^{\prime}$ & Probe, $5^{\prime} \rightarrow 3^{\prime}$ & $\begin{array}{l}\text { Concentration } \\
\text { of oligo per } \\
\text { reaction, } \mathrm{nM} \dagger\end{array}$ \\
\hline $\begin{array}{l}c f b(7) \\
\text { GBS }\end{array}$ & $\begin{array}{l}\text { GGGAACAGATTATGAAA } \\
\text { AACCG }\end{array}$ & $\begin{array}{c}\text { AAGGCTTCTACACGACTA } \\
\text { CCAA }\end{array}$ & $\begin{array}{c}\text { AGACTTCATTGCGTGCCAACCCTGAGAC } \\
\text { 5'-HEX; 3'-BHQ1 }\end{array}$ & $200 / 200 / 200$ \\
\hline $\begin{array}{l}\text { fbps }(8) \\
\text { S. suis }\end{array}$ & $\begin{array}{c}\text { TCCRATRCTGCTCTGCC } \\
\text { ATT }\end{array}$ & $\begin{array}{l}\text { TGATAGTAGAAGTCCAG } \\
\text { CARACT }\end{array}$ & $\begin{array}{c}\text { AATAGCCC"T"GAAAAMCAGCCACWYTTT } \\
\text { GARA } \\
\text { 5'-FAM; 3'-SpC6; "T" = BHQ1 }\end{array}$ & $200 / 200 / 100$ \\
\hline $\begin{array}{l}\text { spy }(9) \\
\text { GAS }\end{array}$ & $\begin{array}{l}\text { GCACTCGCTACTATTTC } \\
\text { TTACCTCAA }\end{array}$ & $\begin{array}{l}\text { GTCACAATGTCTTGGAAA } \\
\text { CCAGTAAT }\end{array}$ & $\begin{array}{c}\text { CCGCAAC"T"CATCAAGGATTTCGTTACCA } \\
\text { 5'-Cy-5; 3'- SpC6; "T" = BHQ2 }\end{array}$ & $300 / 300 / 100$ \\
\hline $\begin{array}{l}\text { RNaseP } \\
(10)\end{array}$ & $\begin{array}{c}\text { AGATTTGGACCTGCGAG } \\
\text { CG }\end{array}$ & $\begin{array}{c}\text { GAGCGGCTGTCCCACAA } \\
\text { GT }\end{array}$ & $\begin{array}{c}\text { TTCTGACCTGAAGGCTCTGCGCG } \\
\text { 5'-FAM; 3'-BHQ1 }\end{array}$ & $400 / 400 / 100$ \\
\hline
\end{tabular}

and $1.5 \mu \mathrm{L}$ of PCR-grade water. The thermal profile for the real-time PCR runs was 1 cycle of $55^{\circ} \mathrm{C}$ for 5 min, 1 cycle of $95^{\circ} \mathrm{C}$ for $10 \mathrm{~min}$, then 40 cycles of $95^{\circ} \mathrm{C}$ for $15 \mathrm{~s}$ and $60^{\circ} \mathrm{C}$ for $1 \mathrm{~min}$. All specimens were tested by real-time PCR for the presence of the human ribonuclease $\mathrm{P}$ (RNaseP) gene to check for the presence of inhibitors. A specimen was considered positive if the cycle threshold $\left(C_{t}\right)$ for 1 of the bacterial targets was $\leq 35$ and was considered negative if the $C_{t}$ was $\geq 40$ for all bacterial targets with $C_{t} \leq 35$ for RNaseP. If $C_{t}$ was between 35 and 40 for the bacterial targets and $\leq 35$ for RNaseP, the specimen is retested; if the result was reproducible, it was considered positive. The lower limits of detection (LLDs) were determined as previously described (11). The LLD of the direct triplex assay ( $3 \mathrm{CFU} / \mu \mathrm{L}$ for $S$. suis, $28 \mathrm{CFU} / \mu \mathrm{L}$ for GBS, and $26 \mathrm{CFU} / \mu \mathrm{L}$ for GAS) were compared with the LLD of the triplex assay conducted on DNA extracted from the same serial dilutions ( $2 \mathrm{CFU} / \mu \mathrm{L}$ for $S$. suis, 5 $\mathrm{CFU} / \mu \mathrm{L}$ for GBS, and $3 \mathrm{CFU} / \mu \mathrm{L}$ for GAS).

Among the specimens tested, 21 were positive for S. suis, 13 for GAS, and 4 for GBS (Table 2). Of the 21
S. suis-positive case-patients, 1 was 4 years of age, 3 were 5-14 years of age, 2 were 15-29 years of age, 9 were $30-49$ years of age, and 6 were $\geq 50$ years of age; $16(76.2 \%)$ were male and $5(23.8 \%)$ were female. Two $(9.5 \%)$ patients died, 14 recovered, and the outcome for 5 was unknown. Eight (61.5\%) of the GAS-positive case-patients were $<5$ years of age and 5 were $5-14$ years of age; $1(7.7 \%)$ patient died, 5 recovered, and the outcome for 7 was unknown. All the GBS-positive case-patients were $\leq 6$ months of age and all recovered. Median time from symptom onset to CSF collection was 2 days (range 1-10 days) for all the patients.

S. suis-positive cases were found among specimens from rural districts in 10/13 regions of the country with $28 \%(6 / 21)$ from the Centre-Est Region and 19\% (4/21) from the Plateau Central Region. All adults with $S$. suis were farmers. Because of the retrospective detection of the etiology, the extent of any direct exposure of the $S$. suis-positive patients to pigs or pork products was unknown and attempts to collect additional information from the patients or their families were unsuccessful.

\begin{tabular}{|c|c|c|c|c|}
\hline \multirow[b]{2}{*}{ Characteristics } & \multicolumn{3}{|c|}{ Patients infected, no. (\%) } & \multirow{2}{*}{$\begin{array}{c}\text { All patients, no. (\%), n } \\
=590\end{array}$} \\
\hline & S. suis, $\mathrm{n}=21$ & S. pyogenes, $\mathrm{n}=13$ & S. agalactiae, $\mathrm{n}=4$ & \\
\hline \multicolumn{5}{|l|}{ Age, $y$} \\
\hline$<5$ & $1(4.8)$ & $8(61.5)$ & $4(100)$ & $307(52)$ \\
\hline $5-14$ & $3(14.3)$ & $5(38.5)$ & 0 & $168(28.5)$ \\
\hline $15-29$ & $2(9.5)$ & 0 & 0 & $64(10.8)$ \\
\hline $30-49$ & $9(42.8)$ & 0 & 0 & $37(6.3)$ \\
\hline$\geq 50$ & $6(28.6)$ & 0 & 0 & $14(2.4)$ \\
\hline \multicolumn{5}{|l|}{ Sex } \\
\hline M & $16(76.2)$ & $9(69.2)$ & $2(50)$ & $332(56.3)$ \\
\hline $\mathrm{F}$ & $5(23.8)$ & $4(30.8)$ & $2(50)$ & $258(43.7)$ \\
\hline \multicolumn{5}{|l|}{ Year CSF collected } \\
\hline 2015 & $5(23.8)$ & $1(7.7)$ & 0 & 87 (14.7) \\
\hline 2016 & $2(9.5)$ & $2(15.4)$ & 0 & $104(17.6)$ \\
\hline 2017 & $6(28.6)$ & $3(23.1)$ & $2(50)$ & $195(33.1)$ \\
\hline 2018 & $8(38.1)$ & $7(53.8)$ & $2(50)$ & $204(34.6)$ \\
\hline Median leukocytes, cells $/ \mathrm{mm}^{3}$ (range) & $400(51-6,250)$ & $1,000(53-8,000)$ & $1,100(800-2,400)$ & $920(50-8,000)$ \\
\hline Median $\mathrm{C}_{\mathrm{t}}$ (range) & $26.1(18.13-35.52)$ & $25.33(14.78-34.71)$ & $23.47(17.24-24.23)$ & $25.33(14.78-35.52)$ \\
\hline
\end{tabular}


Small-scale pig farming is a major economic activity in most parts of Burkina Faso. Although porcine-related occupations, undercooked pork consumption, and exposure to pigs have been identified as major risk factors for $S$. suis infection (5), its occurrence in a wide range of animal species have been reported (2).

DNA extracted from the $S$. suis-positive specimens were used for a multiplex conventional PCR for serotype detection (12). All the specimens were serotype 2 or $1 / 2$ because the method used here could not clearly differentiate serotypes 2 and $1 / 2$. Bacterial isolates from these cases were not available for further characterization. Serotype 2 is believed to cause $74 \%-95 \%$ of human cases of $S$. suis infections reported worldwide, but serotype $1 / 2$ has not been reported to cause disease in humans $(1,2)$.

\section{Conclusions}

Limited data are available regarding the incidence of streptococcal infections in Africa, and the disease burden likely is underestimated, especially for disease caused by $S$. suis. Two reported studies conducted in Togo identified 16 human cases of $S$. suis meningitis during 2010-2015 caused by serotype $2(13,14)$. Another recent study in Madagascar described 2 human cases of $S$. suis meningitis, also caused by serotype 2 (15).

Our study reports 21 cases of $S$. suis meningitis from 2015-2018 in Burkina Faso. S. suis infections more commonly are observed in adult males and are directly correlated with occupational exposure to pigs or pork products $(2,13,15)$. All adult cases reported here were farmers, although their exposure to pigs or pork was unknown. The presence of children among the patients in this study and in previous studies (13) indicates that older children also should be considered at risk. Finding 21 cases of this outbreak-prone zoonotic pathogen in this study raises concern about the incidence of $S$. suis disease in Burkina Faso and in other parts of Africa where pigs are raised. Prospective surveillance for S. suis could help identify farming communities where measures to prevent disease and its potential socioeconomic damages are needed.

\section{About the Author}

Dr. Ouattara is a microbiologist in the Streptococcus Laboratory, National Center for Immunization and Respiratory Diseases, Centers for Disease Control and Prevention, Atlanta, Georgia, USA. His primary research interests include meningitis, invasive streptococcal diseases, bacterial pathogenesis, and global laboratory capacity building.

\section{References}

1. Goyette-Desjardins G, Auger JP, Xu J, Segura M, Gottschalk M. Streptococcus suis, an important pig pathogen and emerging zoonotic agent-an update on the worldwide distribution based on serotyping and sequence typing. Emerg Microbes Infect. 2014;3:e45. https:/ / doi.org/10.1038/ emi.2014.45

2. Dutkiewicz J, Sroka J, Zając V, Wasiński B, Cisak E, Sawczyn A, et al. Streptococcus suis: a re-emerging pathogen associated with occupational exposure to pigs or pork products. Part I-epidemiology. Ann Agric Environ Med. 2017;24:683-95. https://doi.org/10.26444/aaem/79813

3. Gottschalk M, Xu J, Calzas C, Segura M. Streptococcus suis: a new emerging or an old neglected zoonotic pathogen? Future Microbiol. 2010;5:371-91. https://doi.org/10.2217/ fmb.10.2

4. Strangmann E, Fröleke H, Kohse KP. Septic shock caused by Streptococcus suis: case report and investigation of a risk group. Int J Hyg Environ Health. 2002;205:385-92. https:/ / doi.org/10.1078/1438-4639-00165

5. Mai NTH, Hoa NT, Nga TVT, Linh LD, Chau TTH, Sinh DX et al. Streptococcus suis meningitis in adults in Vietnam. Clin Infect Dis. 2008;46:659-67. https:/ / doi.org/10.1086/527385

6. Kambiré D, Soeters HM, Ouédraogo-Traoré R, Medah I, Sangare L, Yaméogo I, et al.; MenAfriNet Consortium. Nationwide trends in bacterial meningitis before the introduction of 13-valent pneumococcal conjugate vaccineBurkina Faso, 2011-2013. PLoS One. 2016;11:e0166384. https:// doi.org/10.1371/journal.pone.0166384

7. Diaz MH, Waller JL, Napoliello RA, Islam MS, Wolff BJ, Burken DJ, et al. Optimization of multiple pathogen detection using the TaqMan array card: application for a population-based study of neonatal infection. PLoS One. 2013;8:e66183. https:/ / doi.org/10.1371/journal. pone. 0066183

8. Srinivasan V, McGee L, Njanpop-Lafourcade BM, Moïsi J, Beall B. Species-specific real-time PCR assay for the detection of Streptococcus suis from clinical specimens. Diagn Microbiol Infect Dis. 2016;85:131-2. https:/ / doi.org/10.1016/ j.diagmicrobio.2016.02.013

9. Kodani M, Yang G, Conklin LM, Travis TC, Whitney CG, Anderson LJ, et al. Application of TaqMan low-density arrays for simultaneous detection of multiple respiratory pathogens. J Clin Microbiol. 2011;49:2175-82. https://doi.org/10.1128/JCM.02270-10

10. Emery SL, Erdman DD, Bowen MD, Newton BR, Winchell JM, Meyer RF, et al. Real-time reverse transcription-polymerase chain reaction assay for SARS-associated coronavirus. Emerg Infect Dis. 2004;10:311-6. https:/ / doi.org/ 10.3201/eid1002.030759

11. Ouattara M, Whaley MJ, Jenkins LT, Schwartz SB, Traore RO, Diarra S, et al. Triplex real-time PCR assay for the detection of Streptococcus pneumoniae, Neisseria meningitidis and Haemophilus influenzae directly from clinical specimens without extraction of DNA. Diagn Microbiol Infect Dis. 2018. https:/ / doi.org/10.1016/j.diagmicrobio. 2018.10.008

12. Kerdsin A, Akeda Y, Hatrongjit R, Detchawna U, Sekizaki T, Hamada S, et al. Streptococcus suis serotyping by a new multiplex PCR. J Med Microbiol. 2014;63:824-30. https:// doi.org/10.1099/jmm.0.069757-0

13. Tall H, Njanpop-Lafourcade BM, Mounkoro D, Tidjani L, Agbenoko K, Alassani I, et al. Identification of Streptococcus suis meningitis through population-based surveillance, Togo, 2010-2014. Emerg Infect Dis. 2016;22:1262-4. https://doi.org/10.3201/eid2207.151511 
14. Prince-David M, Salou M, Marois-Créhan C, Assogba K, Plainvert C, Balogou KA, et al. Human meningitis due to Streptococcus suis in Lomé, Togo: a case report. BMC Infect Dis. 2016;16:651. https:/ / doi.org/10.1186/s12879-016-2006-0

15. Raberahona M, Rasoanandrasana S, Rahajamanana VL, Ranaivo-Rabetokotany F, Andriananja V, Rakotomalala FA, et al. Novel Streptococcus suis sequence type 834 among humans, Madagascar. Emerg Infect Dis. 2018;24:391-2.

https://doi.org/10.3201/eid2402.171138

Address for correspondence: Mahamoudou Ouattara, Centers for Disease Control and Prevention, 1600 Clifton Rd NE, Mailstop H18-B, Atlanta, GA 30329-4027, USA; email: mouattara1@cdc.gov

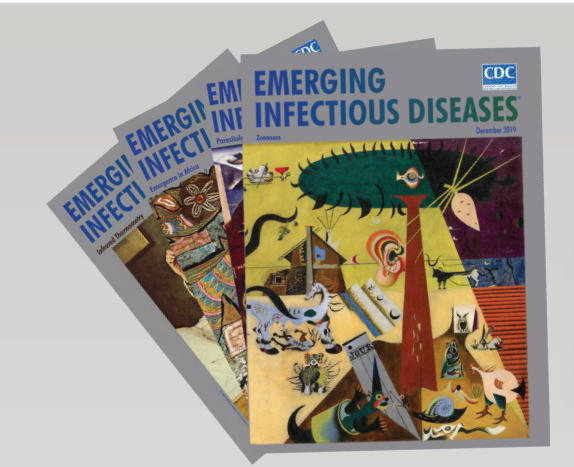

- Seroprevalence and Risk Factors Possibly Associated with Emerging Zoonotic Vaccinia Virus in a Farming Community, Colombia

- Patterns of Transmission and Sources of Infection in Outbreaks of Human Toxoplasmosis

- Global Epidemiology of Buruli Ulcer, 2010-2017, and Analysis of 2014 WHO Programmatic Targets

- Cost-effectiveness of Prophylactic Zika Virus Vaccine in the Americas

- Human Infection with Orf Virus and Description of Its Whole Genome, France, 2017

- High Prevalence of Macrolide-Resistant Bordetella pertussis and ptxP1 Genotype, Mainland China, 2014-2016

Avian Influenza A Viruses among Occupationally Exposed Populations, China, 2014-2016

- Genomic Analysis of Fluoroquinolone- and TetracyclineResistant Campylobacter jejuni Sequence Type 6964 in Humans and Poultry, New Zealand, 2014-2016

- Streptococcus suis-Associated Meningitis, Bali, Indonesia, 2014-2017

- Epidemiologic, Entomologic, and Virologic Factors of the 2014-15 Ross River Virus Outbreak, Queensland, Australia

Multicountry Analysis of Spectrum of Clinical Manifestations in Children $<5$ Years of Age Hospitalized with Diarrhea

- Sheep as Host Species for Zoonotic Babesia venatorum, United Kingdom

- Half-Life of African Swine Fever Virus in Shipped Feed
December 2019

- Zika Virus IgM 25 Months after Symptom Onset, MiamiDade County, Florida, USA

- Divergent Barmah Forest Virus from Papua New Guinea

- Animal Exposure and Human Plague, United States, 19702017

- Sentinel Listeriosis Surveillance in Selected Hospitals, China, 2013-2017

- Economic Impact of Confiscation of Cattle Viscera Infected with Cystic Echinococcosis, Huancayo Province, Peru

- Predicting Dengue Outbreaks in Cambodia

- Cat-to-Human Transmission of Mycobacterium bovis, United Kingdom

- Evolution of Highly Pathogenic Avian Influenza A(H5N1) Virus in Poultry, Togo, 2018

- West Nile Virus in Wildlife and Nonequine Domestic Animals, South Africa, 2010-2018

- Highly Pathogenic Avian Influenza A(H5N8) Virus in Gray Seals, Baltic Sea

- Bagaza Virus in Himalayan Monal Pheasants, South Africa, 2016-2017

- Influenza A(H1N1)pdm09 Virus Infection in a Captive Giant Panda, Hong Kong

- Middle East Respiratory Syndrome Coronavirus Seropositivity in Camel Handlers and their Families, Pakistan

- Distantly Related Rotaviruses in Common Shrews, Germany, 2004-2014

To revisit the December 2019 issue, go to: https://wwwnc.cdc.gov/eid/articles/issue/25/12/table-of-contents 